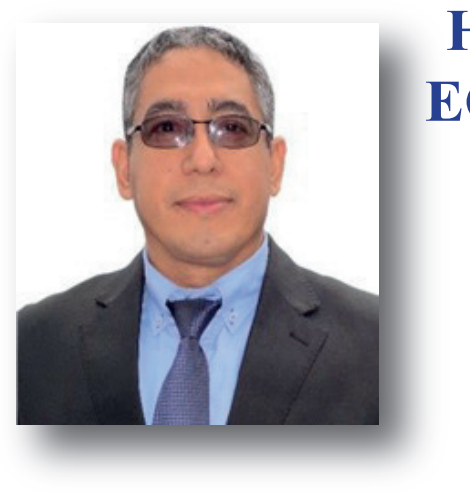

\title{
HACIA OTRO PARADIGMA DE ECONOMÍA POLÍTICA DEL CAFÉ \\ Y DESARROLLO HUMANO \\ EN EL OCCIDENTE \\ DE HONDURAS.
}

\author{
PhD. JORGE HUMBERTO ORELLANA PEÑA \\ jorge.orellana@unah.edu.hn \\ Centro Regional Universitario de Occidente \\ UNAH - CUROC \\ ORCID: 0000-0002-8669-6090
}

DOI: $10.5377 /$ rpdd.v5i1.11965

Recibido: enero, 2019

Aceptado: marzo, 2019

\section{RESUMEN}

Fiste estudio propone un debate alternativo de economía política del café y desarrollo humano en el occidente de Honduras. Se basó en la comprensión de los significados, prácticas y contribuciones de la caficultura y los procesos desarrollistas. La metodología tuvo un enfoque principalmente cualitativo. Algunas percepciones fueron traducidas al lenguaje numérico para su interpretación. Se utilizaron software como Atlas. ti y SPSS. Se realizaron entrevistas a familias productoras de café, técnicos, directivos de instituciones cafetaleras y otros agentes que intervienen en procesos de desarrollo. La fórmula estadística aplicada fue de 378 participantes, distribuidos de forma proporcional en Copán, Ocotepeque y Lempira. El estudio contempló visitas de campo, observación participante, grupos focales y una etapa etnográfica.

Los resultados muestran una serie de dificultades que enfrentan las familias productoras y se proponen formas diferentes de intervención y comprensión de la realidad. La caficultura ayuda a solventar una serie de necesidades, pero aún presenta retos en temas del desarrollo humano como la participación, toma de decisiones, encadenamiento del café con otras actividades, procesos de organización y fortalecimiento institucional. Es una preocupación el cambio climático, el manejo de aguas mieles, pulpa del café, erosión del suelo, tala del bosque y cuidado de las 


\title{
HACIA OTRO PARADIGMA DE ECONOMÍA POLÍTICA DEL CAFÉ Y DESARROLLO HUMANO \\ EN EL OCCIDENTE DE HONDURAS.
}

fuentes de agua. La revisión de las premisas de intervención, el mejoramiento de la socioeconomía familiar, la búsqueda de la calidad y diversificación, los cafés diferenciados y los procesos de certificación, son posibilidades y alternativas que pueden conducir al establecimiento institucionalizado de una cultura del café en el occidente de Honduras.

\section{PALABRAS CLAVE}

Caficultura, región, occidental, desarrollo, deconstrucción, humano, descolonización, familias, producción, alternativa

\begin{abstract}
This study proposes an alternative debate on the political economy of coffee and human development in western Honduras. It was based on an understanding of the meanings, practices and contributions of coffee growing and development processes. The methodology had a mainly qualitative approach. Some perceptions were translated into the numerical language for its interpretation. Software such as Atlas ti and SPSS was used. Interviews were carried out with coffee producing families, technicians, managers of coffee institutions and other agents involved in development processes. The statistical formula applied was 378 participants, distributed proportionally in Copán, Ocotepeque and Lempira. The study included field visits, participant observation, focus groups and an ethnographic phase.
\end{abstract}

The results show a series of difficulties faced by the producer families and propose different forms of intervention and understanding of reality. Coffee farming helps solve a series of needs, but still presents challenges in human development issues such as participation, decision-making, linking coffee with other activities, organizational processes and institutional strengthening. Climate change, the management of honey water, coffee pulp, soil erosion, forest clearing and care of water sources are a concern. The revision of intervention premises, the improvement of family socioeconomy, the search for quality and diversification, differentiated coffees and certification processes are possibilities and alternatives that can lead to the institutionalized establishment of a coffee culture in western Honduras.

\section{KEYWORDS}

Coffee farming, region, western, development, deconstruction, human, decolonization, families, production, alternative 


\section{INTRODUCCIÓN}

Este artículo presenta una valoración de la economía política del café y sus contribuciones al desarrollo humano de la región occidental de Honduras. Desde la percepción de las familias productoras de café, recoge las preocupaciones en temas organizacionales e institucionales, socioeconómicos y ambientales. Es un llamado a la reflexión; es buscar la comprensión de uno de los rubros que aportan ingresos significativos. El occidente de Honduras produce el $30 \%$ de la caficultura nacional, sin embargo, es una región que sigue sumergida en una serie de desigualdades sociales.

La presente investigación ha buscado acercarse a procesos de deconstrucción cultural y descolonización epistemológica que induzcan nuevas formas de intervención; nuevos paradigmas o modelos que orienten caminos diferentes, nuevas compresiones para que puedan diferenciarse alternativas de desarrollo y alternativas al desarrollo. Desde hace siete décadas, las concepciones clásicas del desarrollo han contado con una serie de revisiones y críticas, pues el mismo ha estado plagado de una serie de adjetivos que lo hacen flexible y adaptable; su discurso y su práctica social han penetrado por diferentes medios. Por tal razón, es imprescindible la búsqueda de otras miradas de la realidad, es preguntase por qué diferentes programas y proyectos de desarrollo no han logrado reducir las precarias condiciones en las comunidades; por qué hay tanta pobreza en medio de abundante riqueza.

El estudio fue realizado en los departamentos de Copán, Ocotepeque y Lempira entre 2014 y 2018; recoge las recomendaciones y preocupaciones de familias productoras de café y demás agentes que están alrededor de la caficultura y las intervenciones del desarrollo. El tema corresponde a una tesis doctoral que vincula la caficultura con el desarrollo humano. La finalidad ha sido, buscar desde los espacios académicos, desde la familia misma, desde quienes animan procesos, reflexionar y fomentar un pensamiento que desnaturalice la vergonzosa exclusión social que sufre esta sociedad y, a la vez, buscar insumos para construir una nueva epistemología en la intervención; un modelo alternativo de economía política del café y desarrollo humano que privilegie los espacios locales y coloque a las personas por encima de cualquier pretensión material y de racionalidad económica. La investigación busca acercarse a una verdadera justicia cognitiva para encontrar formas alternativas de bienestar social; es una invitación para institucionalizar una cultura del café en cada región del país; una identidad cultural cafetalera que invite al sí se pueden hacer bien las cosas; desde los niños, los jóvenes y adultos, juntos construimos sueños y esperanzas con visiones incluyentes, biocéntricas, espirituales y, especialmente, con un irrestricto respeto por la sostenibilidad de todas las formas de vida. 


\section{HACIA OTRO PARADIGMA DE ECONOMÍA POLÍTICA DEL CAFÉ Y DESARROLLO HUMANO \\ EN EL OCCIDENTE DE HONDURAS.}

\section{MÉTODO}

\section{Diseño}

La investigación tuvo un diseño principalmente cualitativo, sin embargo, algunas percepciones fueron traducidas al lenguaje numérico y fue utilizada la estadística descriptiva con medidas de tendencia central, principalmente la moda y la media. Se aplicó una fórmula para el cálculo de muestras con un 95\% de confianza y un margen de error del 5\%, la población considerada fue de 24716 productores, con datos del Ihcafé de 2016.

La etapa cualitativa se basó en entrevistas que describieron la realidad de las familias productoras de café. Esto permitió el reconocimiento del otro, familias portadoras de valores, sueños y esperanzas. La realidad estudiada se basó en la heterogeneidad, por cuanto, no se trató de buscar una sola verdad, sino múltiples verdades particulares. Para los datos cualitativos se utilizó el programa Atlas ti. Y para el cálculo de la moda y la media fue utilizado el programa Statistical Product and Service Solutions (SPSS).

\section{Población}

Los actores relevantes de esta investigación son, en primer lugar, las familias productoras de café de la región occidental de Honduras. En segundo lugar, todos aquellos actores que intervienen en los procesos de gestión del desarrollo humano y, especialmente, en la economía política del café: Directores y técnicos de diferentes organizaciones no gubernamentales relacionados con procesos de desarrollo o con la economía del café. Gobierno local, cooperativas o asociaciones de café, fundaciones o instituciones públicas y privadas de café y sectores académicos.

\section{Entorno}

Se escogieron cinco municipios por cada departamento representativos de la producción regional. Los cuestionarios y entrevistas fueron aplicados en: Corquín, Florida, Santa Rita, San Pedro y Cucuyagua en Copán. En Lempira: La Iguala, Lepaera, La Unión, Gracias, San Rafael. En Ocotepeque: San Marcos, Sensenti, La Labor, San Francisco del Valle y Mercedes. Debido a que la "Región Copán" del Ihcafé contempla algunos municipios de Santa Bárbara e Intibucá, se incluyeron entrevistas y cuestionarios en Naranjito Santa Bárbara y San Juan, Intibucá.

La etapa etnográfica de este estudio fue realizada en la finca de café de la familia Zelaya en el sector "El Coyolar" de la comunidad El Níspero del municipio de Cucuyagua, Copán. La permanencia fue de dos semanas alternas durante los meses de noviembre y diciembre de 2017. 


\section{Intervenciones}

Este estudio empleó técnicas de investigación cualitativa y cuantitativa. En su fase cualitativa, el alcance fue descriptivo, partiendo de las percepciones provenientes de las familias productores. Se aplicaron entrevistas y se realizaron giras de campo, observaciones y grupos focales. Para esta fase se empleó el método etnográfico, el cual permitió la convivencia durante dos semanas con las familias productoras de café.

En su fase cuantitativa, las frecuencias producto de las percepciones fueron traducidas a lenguaje numérico (Sampieri et. al., 2006, 2014), esto permitió por medio del programa SPSS, extraer frecuencias que fueron presentadas gráficos y cuadros.

\section{Análisis del estudio}

Para la fase cualitativa se utilizó el programa Atlas. ti. Se emplearon cuatro familias de categorías: Monocultura del café, caficultura y desarrollo humano, organización e institucionalidad, caficultura y ambiente. Cada una de estas familias contempló una serie de categorías. Para el análisis se utilizaron 30 entrevistas, las cuales se codificaron de acuerdo con su relación con cada categoría. El programa Atlas ti., permitió crear códigos y citas textuales que sirvieron para teorizar los resultados.

Para la fase cuantitativa o numérica se diseñó una plantilla en el programa SPSS. El cuestionario para este propósito se aplicó a una muestra representativa de productores de café y de acuerdo con fórmulas estadísticas. La combinación de herramientas cualitativas y cuantitativas fue con el propósito de poder realizar una mejor triangulación y validación de los resultados del estudio.

\section{ÉTICA}

La investigación contempló el conocimiento informado de los actores clave. En todo momento se explicó a los participantes acerca de los objetivos de la investigación. El uso de grabadoras y cámaras fotográficas se hizo con el consentimiento de los participantes. Se explicó que el estudio de doctorado era para propósitos eminentemente académicos, investigación que estará disponible para todo público.

\section{RESULTADOS DEL ESTUDIO}

La cadena productiva del café representa una fuente importante de divisas que contribuye a la búsqueda de la estabilidad macroeconomía nacional. La dinámica económica del café mueve una gran cantidad de negocios de diferente índole 


\section{HACIA OTRO PARADIGMA DE ECONOMÍA POLÍTICA DEL CAFÉ Y DESARROLLO HUMANO \\ EN EL OCCIDENTE DE HONDURAS.}

(alimentos, textiles, maquinaria, insumos, etc.) Alrededor de la cadena del café están los procesos de integración de estructuras de productores, procesos de certificación, calidad y cafés diferenciados, así como iniciativas emprendedoras impulsadas por asociaciones de mujeres.

Dentro de la economía política del café existen dos alternativas para las familias productoras; por un lado, está una economía agroexportadora que invita a la participación en el mercado internacional, esta es controlada por las empresas exportadoras y por diferentes cooperativas cafetaleras que realizan procesos de intermediación de la producción. Por otra parte, existe una economía más social hacia lo interno de la finca, en la cual las familias invierten sus ahorros en mantenimiento, en algunos procesos de diversificación y en ampliación y mejoramiento de sus fincas.

Este estudio tiene dos ejes centrales de análisis; "economía política del café" y "desarrollo humano". De ello, se han derivado las siguientes categorías: monocultura del café, caficultura y desarrollo humano, organización e institucionalidad, caficultura y ambiente. Cada una de ellas contempló el análisis de diversas subcategorías que proceden de la comprensión que familias productoras y demás actores tienen del tema.

\section{La economía política del café}

La economía del café aporta beneficios sustanciales al país. Esta economía está representada por dos instituciones: El Instituto Hondureño del Café (IHCAFÉ) y El Fondo Cafetero Nacional (FCN). Además, existen tres organizaciones gremiales: La Asociación Hondureña de Productores de Café (AHPROCAFÉ), la Asociación Nacional de Caficultores de Honduras (ANACAFEH), la Unión de Cooperativas de Servicios Agropecuarios Limitada (UNIOCCOP) y La Central de Cooperativas Cafetaleras de Honduras ( $\mathrm{CCCH})$. Toda la institucionalidad se rige por las políticas cafetaleras emitidas por el Consejo Nacional del Café (CONACAFÉ). La búsqueda de nuevas variedades, la asistencia técnica, los procesos de formación y el acceso al financiamiento son parte de los quehaceres de la institucionalidad cafetalera.

Las instituciones mencionadas son financiadas por los productores. Por cada quintal exportado de 46 kilogramos, se retienen 13.25 dólares, de los cuales, 1 dólar es para el funcionamiento del Ihcafé; 1.75 dólar es para el Fondo Cafetero Nacional. 1.50 dólares son retenidos para el pago de préstamos asumidos por el Ihcafé y 9 dólares restante es devuelto a los productores. Desde la percepción de los consultados, estas retenciones, más los descuentos por humedad del café lesionan su economía familiar. Por tal razón, existe una percepción generalizada en el sentido de que es el mismo 
productor que mantiene la institucionalidad cafetalera y es el que menos se beneficia dentro de la cadena de valor.

\section{El desarrollo humano en el occidente de Honduras}

La implementación de los modelos de desarrollo y sus diferentes estrategias no han resuelto los bajos indicadores de bienestar social en el occidente de Honduras. Los vacíos que ha dejado cada intervención es duplicidad de esfuerzos técnicos y financieros. Cada organización de desarrollo ha impuesto su propia agenda de trabajo.

La familia productora, al final se convierte en subsidiaria del Estado al invertir sus ingresos en salud, educación y otras necesidades básicas. La región occidental sigue siendo una de las zonas con mayor desigualdad y pobreza en el país. Los diferentes informes del Programa de las Naciones Unidas para el Desarrollo (PNUD) han revelado la pobreza de decenas de municipios. Esta pobreza se traduce en el poco acceso a la educación, a fuentes de empleo, a servicios de salud, a una vivienda digna, entre otros. Esto ha implicado, que cientos de jóvenes (y ahora productores) hayan tenido que emigrar hacia Estados Unidos, teniendo un impacto directo en la recolección de la cosecha del café.

Las organizaciones no gubernamentales comenzaron sus estrategias de intervención en el occidente de Honduras en la década del ochenta del siglo XX. Si bien es cierto han contribuido a mejorar los procesos de organización y algunas iniciativas de incidencia política, estas no han logrado resolver el problema de exclusión, puesto que, sus estrategias están desvinculadas de otras actividades productivas y de otros agentes del desarrollo (gobiernos locales, técnicos y directivos, sistema educativo, entre otros). Las organizaciones no gubernamentales de desarrollo dependen de la agenda que le impone su fuente de financiamiento, estas no responden a las necesidades más urgentes de las comunidades, por tal razón, sus impactos en el bienestar humano son casi imperceptibles. Estudios académicos en el occidente de Honduras han concluido que este ha sido el laboratorio más grande en iniciativas y estrategias de intervención en nombre del desarrollo. Por tal razón, la economía del café y el desarrollo humano, necesita de nuevas interpretaciones (llámese modelos, paradigmas, premisas o estrategias) que contribuyan a construir caminos propios para el bienestar de las familias de esta parte del país.

\section{Categoría 1: Las monoculturas que condicionan la cadena productiva del café}

Para el análisis de la "monocultura del café" se consideraron diversos elementos: visión del mundo, las significaciones del café, el desplazamiento de otros 


\section{HACIA OTRO PARADIGMA DE ECONOMÍA POLÍTICA DEL CAFÉ Y DESARROLLO HUMANO \\ EN EL OCCIDENTE DE HONDURAS.}

cultivos y las monoculturas propias del pensamiento desarrollista. En las entrevistas con familias productoras se pudo constatar que prevalece una visión mercadológica de la realidad, las intervenciones del desarrollo están enfocadas bajo una racionalidad económica en la cual impera un lenguaje de competencia, productividad y de inserción en el mercado internacional. Para comprender esta y otras categorías se utilizó el método etnográfico, lo cual implicó la convivencia con una familia productora en el departamento de Copán.

En el primer día, después de participar en labores de recolección y, por la tarde, despulpar el café de ese día, la familia se dispuso a cenar y aceptaron dialogar acerca del estudio realizado. Las preguntas no siguieron un orden formal, surgieron en la medida que se dialogaba con los participantes. Se comenzó a preguntar qué significa el café para ellos. "El café representa esperanza al final de cada año; es pasión y compromiso, es medicina y fuente de trabajo" (Participante 1). En su esencia ontológica, el café es más que un factor estrictamente económico. "Nosotros con el café nos ayudamos un poquito, podemos comprar aunque sea pastillas, no decimos que nos sobra para ir a clínicas privadas, pero nos ayuda a calmar algun dolor. Hemos logrado ir mejorando la casa, y a veces, si los precios nos favorecen, metemos otra luchita (parcela) más de finca" (Participante 2). En medio de la conversación intervenían y recalcaban que el futuro del café es incierto, "los precios siempre los pone el intermediario, nunca nosotros. Mire ahora lo que tenemos que invertir para la roya o la broca, al final, lo poquito que nos queda se tiene que gastar en insumos para la finca" (Participante 1).

La cena era servida; frijoles, pacayas con huevo, queso, café y tortillas tostadas. Unos trozos de madera servían de asientos, un candil alumbraba la improvisada cocina. Poco a poco, los demás miembros de la familia fueron participando de la conversación. Uno de los hijos comentaba que se espera que el café ayude a su economía familiar, que los compromisos que asumen, muchas veces no se pueden pagar al final de la cosecha. "Aunque uno quiera meterse a cultivar otras cositas, no ajusta con lo que sale del café. Nosotros tenemos que mantener esa burocracia de las instituciones, aparte de eso, nos quitan por la humedad del café; la retención no la dan a tiempo cuando uno la ocupa. Mire aquí por ejemplo, si uno quiere cultivar maíz y frijoles es complicado, porque terminan robándose todo... porque uno vive lejos de la finca, ni las pacayas ni guineos deja la gente" (Participante 3).

La actividad productiva se traduce en un solo cultivo para generar ingresos, bajo una visión de competencia económica que responde a un modelo de desarrollo que privilegia el mercado y el capital. Existe, por lo tanto, una monocultura dominante que condiciona la realidad (Santos, 2012; Santos, 2010). 
Detrás de la actividad productiva del café, siempre ha estado un pensamiento puramente económico, ese pensamiento es el que ha condicionado todo modelo de desarrollo (Hunt, 1989; Hettne, 1990; Bustelo, 1992, 1998; Hidalgo, 1998), y lejos de esas pretensiones ha quedado el bienestar humano. Por consiguiente, las familias productoras de café, al ser rehenes de una visión mercadológica de la realidad, al desplazar otros cultivos con el afán de ser competitivos con la producción de café y al tener premisas de las formas clásicas de comprender el desarrollo, no distinguen otras alternativas (de pensamiento, organización, intervención, participación, toma de decisiones) que puedan conducir a mejorar sus condiciones y a dinamizar los beneficios que resultan de su actividad. Por lo cual, ha existido desde hace décadas, una pirámide de desigualdad (Carranza, 2012) que se evidencia entre quienes hacen el mayor esfuerzo y quienes se quedan con la mayor cantidad de ingresos producto de la actividad cafetalera.

\section{Categoría 2: La caficultura y el desarrollo humano en el occidente de Honduras}

La actividad cafetalera en Honduras representa el 30\% del Producto Interno Bruto agrícola (PIB) y el 5\% del PIB nacional (IHCAFÉ, 2017). 105000 productores aproximadamente generan un millón de empleos directos, al menos durante la época de cosecha. En la temporada 2018 - 2019 se exportaron 8.9 millones de sacos de 46kg., lo cual representó el ingreso de al menos 950 millones de dólares; los principales destinos de las exportaciones fueron Europa con 65\% y Estados Unidos de Norteamérica con 26\% (IHCAFÉ, 2019). El café se produce en 15 de los 18 departamentos de Honduras. El occidente de Honduras aporta el 30\% de la producción nacional y son cerca de 30000 familias dedicadas a esta actividad, cada una, en promedio, posee entre 3 y 5 manzanas (Carranza, 2012). A pesar de los beneficios económicos que produce el café, este presenta marcadas asimetrías en sus procesos de acopio, intermediación y comercialización. Ha existido un debate si las familias productoras de café se consideran pobres. Por ejemplo, Jansen (1993) ha planteado que una persona que se dedica a la caficultura no puede considerársele marginada ni excluida, puesto que siempre necesitará de capital para iniciar una finca y un marginado no posee un sistema de relaciones sociales y comerciales (p. 27).

Los cuestionarios aplicados en este estudio muestran que el $77.1 \%$ de los productores no se consideran pobres. Para la mayoría de ellos, la pobreza tiene otros significados, por ejemplo, dedicarse a un solo cultivo, provocar daños a la naturaleza, no tener buena actitud, tener en la mente la idea de ser pobre. Esto obliga a redefinir conceptualmente la pobreza (O’Neill, 2009; Shiva, 2006) para que nos acerque a otras realidades y concepciones. 


\section{Gráfico 1: ¿Desde su percepción usted y su hogar se consideran pobres?}

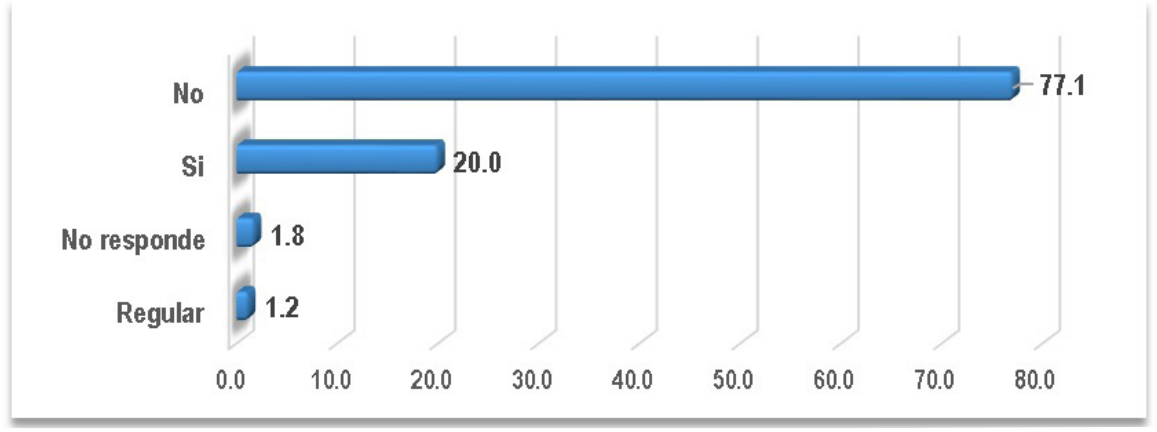

Fuente: Propia con datos de cuestionario UNAH - 2017/2018

Las estrategias de desarrollo de las últimas décadas, implantaron un régimen de representación del sujeto siempre necesitado. No se puede soslayar el hecho de que, por un sistema de exclusión, existen personas empobrecidas en el occidente de Honduras. La poca inversión estatal, la corrupción generalizada y la poca transparencia, los rezagos en el sistema educativo, los pocos avances en infraestructura productiva, la inexistencia de encadenamiento con otros factores de la producción, la economía "informal", el escaso valor agregado, la duplicidad de esfuerzos técnicos y financieros, las medidas populistas y el clientelismo político, son formas de empobrecimiento para las familias productoras. Por tal razón, la pobreza no puede ser analizada como un concepto abstracto o un constructo y una invención de una civilización particular (Rahnema, 1996); "es más una cuestión de tomar menos que de añadir una cantidad insignificante a lo que se da" (Shiva, 2006, p. 9).

Gráfico 2: ¿Cuáles de los siguientes factores considera usted que son causa de empobrecimiento de las familias del occidente de Honduras?

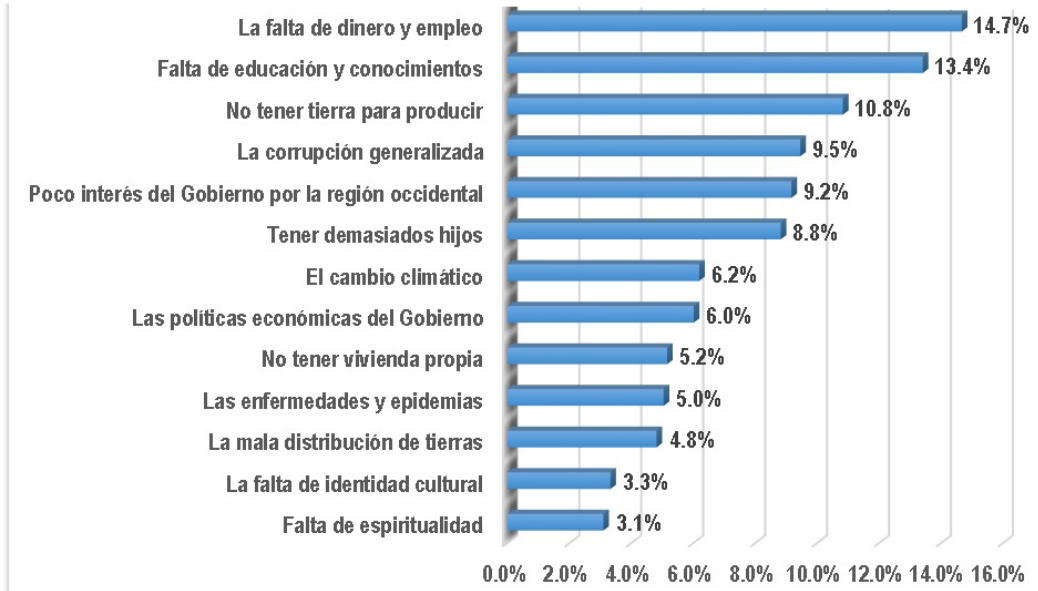

Fuente: Propia con datos de cuestionario UNAH - 2017/2018 
Desde la segunda mitad del siglo XX se creyó que el desarrollo resolvería los problemas de desigualdad y pobreza en el mundo. Sin embargo, todas sus promesas nunca se cumplieron. Detrás del desarrollo siempre estuvo el afán de promover un crecimiento económico sin restricciones, con daños considerables a la Naturaleza y a todas las formas de vida. Poco a poco, al Estado se le fue excluyendo del control de la economía quedando en manos del mercado. Por tal razón, los proyectos de desarrollo siempre promovieron una racionalidad económica y mercadológica. En la caficultura siempre se ha buscado competir en un mercado que impone los precios del café. Este modelo neo extractivista lejos de conducir al bienestar humano, causa explotación sin control de la tierra; contamina el agua y daña todo tipo de ecosistema. Por tal razón, el Estado ha dejado de invertir en servicios de salud, en educación y en acceso a una vivienda digna, puesto que su rol se ha limitado a crear las condiciones para que operen los grandes capitales sin ningún tipo de control. En ese sentido, la familia productora, al no tener acceso a los servicios básicos para su vida, se ha convertido en subsidiaria de un Estado cada vez más precario en términos del llamado desarrollo humano.

Alrededor de la caficultura están las familias de cortadores que buscan aprovechar la época de cosecha. Durante el trabajo de campo, se indagó a los cortadores, hombres y mujeres acerca de su percepción del desarrollo y bienestar humano. "Aquí nosotros tenemos que incluir a todos los miembros de la casa, porque entre todos cortamos más y conseguimos algo de dinero para la comida por lo menos" (Cortadora 1). En los cuestionarios aplicados, el 78\% de los consultados utilizan niños en sus procesos de recolección y clasificación del grano. "A nosotros nos dicen que es prohibido traer niños, pero esto lo hemos hecho siempre, enseñarle desde pequeño a trabajar, sino se quedan de vagos o se meten en drogas desde pequeños, por eso mejor que trabajen desde niños" (Cortadora 2). Un vehículo recoge los cortadores de aldeas vecinas o simplemente esperan en el camino, desde temprano, preparan en sus casas lo poco que pueden llevar de alimentos. A las seis de la mañana llegan a la finca. "El patrón nos dice cuál es la parcela que nos toca, nos vamos todos y vemos qué tan llenos están los palos, a veces nos decepcionamos, porque el corte no está tan bueno. Lo primero que hacemos es comer; comemos temprano porque no perdemos tiempo. Comer a las once o a las doce no nos gusta porque nos da pereza y nos baja sueñito. Le echamos desde temprano y no paramos hasta las tres que entregamos el café para que lo cuenten" (Cortador 3).

Los niños van recogiendo los granos del suelo, sienten cansancio, recogen leña, juegan con cualquier cosa que encuentran, algunos cortan medio galón, los más grandecitos se cortan uno o dos galones en el día. Es parte de su vida, es tradición y es aprendizaje. En las visitas a distintas fincas de café del occidente del país, se tuvo la oportunidad de conocer a mujeres a cargo de todo el proceso productivo. Han 


\section{HACIA OTRO PARADIGMA DE ECONOMÍA POLÍTICA DEL CAFÉ Y DESARROLLO HUMANO \\ EN EL OCCIDENTE DE HONDURAS.}

emprendido procesos de emprendimiento y han avanzado en el valor agregado del café. Reconocen que el café les trae un beneficio económico en cada cosecha, pero no es suficiente para todas las necesidades que hay que cubrir. "Gracias a Dios tenemos esto para vivir, hay otra gente con mayores problemas, pero el café nos sirve para salir de los apuros, por lo menos es una esperanza. Quisiéramos mejorar la finca; poner electricidad, hacer patios más grandes, pero los precios del café no ayudan y a veces solo sacamos los gastos de mantenimiento, hoy todo está caro; los insumos, los foliares, los trabajadores que ya no quieren trabajar barato. Mire que a veces las cooperativas ofrecen abono y fertilizantes, pero nos sale muy caro, porque ellos tienen que ganarle también" (Productora, El Níspero, Cucuyagua Copán).

Si el desarrollo humano se mide en función de los ingresos familiares, entonces la familia productora tiene rezagos considerables. Los cuestionarios aplicados revelaron que los que más se benefician de la cadena productiva son los intermediarios y las empresas exportadoras. Se suma a ello la diversidad de problemas que enfrentan año con año en la cadena de valor del café.

\section{Grafico 3. ¿Cuáles de los siguientes factores considera usted que están afectándole en la cadena productiva del café?}

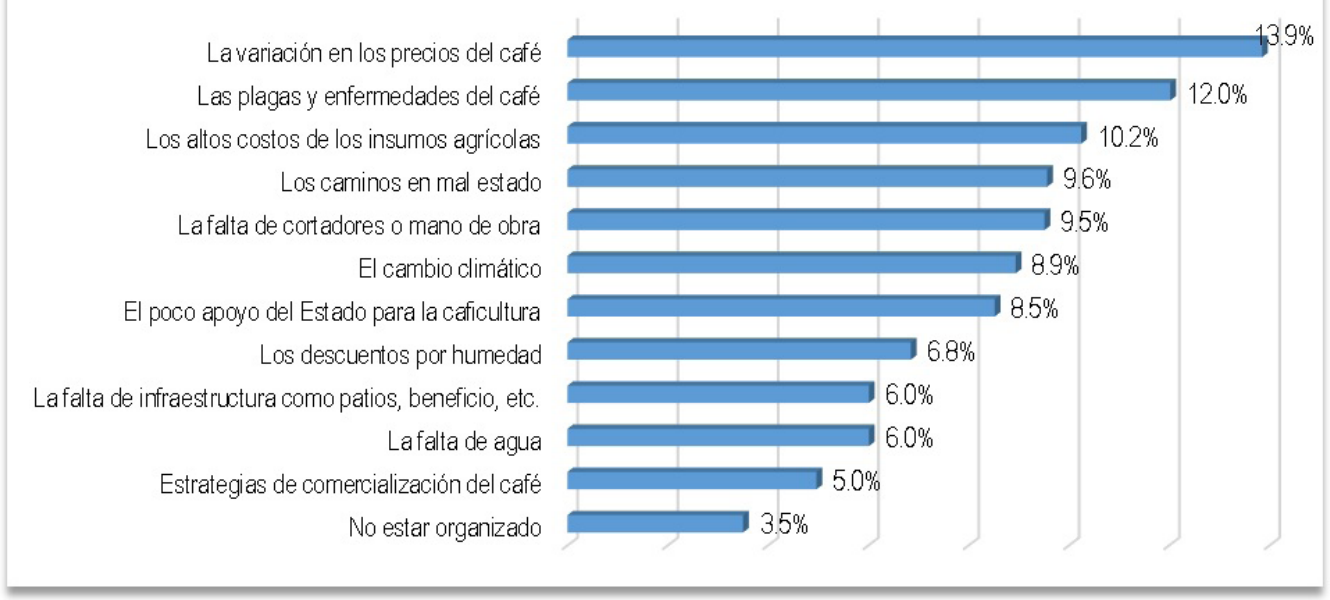

Fuente: Propia con datos de cuestionario UNAH - 2017/2018

Los principales problemas que enfrentan los productores, son externos a ellos y ejercen poco control. El precio del café se decide en el mercado internacional, las plagas y enfermedades tienen un vínculo muy estrecho con el cambio climático $\mathrm{y}$ el precio de los insumos es parte de una competencia comercial sin ninguna 
intervención e injerencia de la institucionalidad. En términos de desarrollo humano existen otras preocupaciones en la actividad cafetalera. Cada vez más la familia se ha decidido por un solo cultivo. Ya no se produce maíz, arroz y frijoles. Se ha dejado de producir plátanos, bananos y hortalizas. En poco tiempo esto puede derivarse en problemas de alimentación en el occidente del país. Si consideramos que el verdadero bienestar humano tiene que ver con ambientes libres de contaminación, con el pleno goce de las libertades humanas, con participación, con procesos de organización y de incidencia en las políticas púbicas, entonces, se puede afirmar que la caficultura tiene todavía un reto que debe enfrentar.

Lareducción delas desigualdades socialesnecesita, quelacaficulturapuedaestar encadenada con otros actores relevantes. "Hay gente que mejoró comprando su carrito, otros, comprando más terreno para fincar, de varias formas, pues ha salido adelante con este producto" (Caficultor, San Pedro, Copán, 2017). Para encontrar beneficios directos al llamado desarrollo humano, la caficultura necesita promover una mejor participación en las estructuras de poder, visibilizar el papel de la mujer en las actividades agrícolas y de emprendimiento, mejorar el trabajo de la gente en las condiciones más justas, buscar mecanismos para la despolitización institucional alrededor de la caficultura, mejor la atención y acceso a oportunidades desde el Estado, mejoramiento en procesos de formación y cualificación en todos los eslabones de la cadena productiva.

Para lograr verdaderos procesos de "desarrollo humano" deberá incluirse un esfuerzo de descolonización epistemológica y de deconstrucción cultural en los procesos de intervención. Deben enfrentarse las variaciones de los precios internacionales, las plagas, enfermedades y cambio climático, así como los altos costos de los insumos agrícolas, el mejoramiento de las vías de comunicación y los problemas derivados de la escasez de mano de obra. La caficultura debe volver la mirada hacia la diversificación productiva, hacia el encadenamiento con otras actividades económicas, hacia procesos de organización que permitan avanzar en calidad, certificación, cafés diferenciados y, a acortar parte de los eslabones de su cadena de valor.

\section{Categoría 3: Los procesos organizativos e institucionales dentro de la caficultura regional}

La asistencia técnica y el acceso al financiamiento son parte de los retos de los procesos organizativos e institucionales. Del total de consultas, un $48.9 \%$ considera que ha mejorado su finca a raíz de la asistencia técnica recibida de instituciones cafetaleras o de cooperativas cafetaleras, $40.7 \%$ adujo nunca haber recibido asistencia técnica. Desde la perspectiva institucional, es imposible llegar directamente a todos los productores, por lo cual, se recurre a "días demostrativos" para capacitar a la mayor cantidad de productores. 


\section{HACIA OTRO PARADIGMA DE ECONOMÍA POLÍTICA DEL CAFÉ Y DESARROLLO HUMANO \\ EN EL OCCIDENTE DE HONDURAS.}

El sistema financiero siempre ha considerado a la agricultura como un sector de alto riesgo; $51.1 \%$ de los consultados aducen que el acceso a créditos es difícil. A esto se suma el poco apoyo que, desde la percepción de los productores, tienen del gobierno municipal. Con respecto a las políticas cafetaleras del Estado, el $52.4 \%$ de los consultados manifestó que no han contribuido con el rubro. $51.9 \%$ de la muestra adujo que la política pública se discute en un grupo reducido de actores, sin participación real del gremio cafetalero.

A pesar de ello, existen procesos organizativos interesantes que buscan acortar los eslabones de la cadena productiva. Se ha dado valor agregado al café por medio de diferentes marcas, tienen compradores directos y están fortaleciendo los cafés de alta calidad a través de procesos de certificación. Sin embargo, las estrategias de coordinación aun presentan enormes desafíos. Existe una desvinculación en las intervenciones del desarrollo que realizan oficinas del Gobierno, Academia, ONG, gobiernos locales e instituciones cafetaleras. Esto representa un desafío si queremos mejorar los indicadores de bienestar en la región. En ese sentido, las comunidades y las familias productoras son quienes deben definir los fines de toda estrategia desarrollista, deben ser los actores relevantes que construyen juntos sus propios caminos hacia el futuro.

\section{Categoría 4: Caficultura y ambiente}

La caficultura nacional presenta una serie de riesgos ambientales que son inherentes a las prácticas tradicionales de las familias productoras. Para algunos, existe una consciencia ambiental al usar abonos orgánicos y químicos menos dañinos a la naturaleza, para otros, hay un total desconocimiento. El manejo de las aguas mieles y de la pulpa son factores latentes que afectan el entorno ambiental.

La tala del bosque para ampliar la frontera agrícola, la pérdida de la fauna por regulación masiva de sombra, son prácticas frecuentes año con año en la región. El beneficiado en las cooperativas y empresas exportadoras pueden ser alternativas para mitigar los impactos al ambiente provocados por la miel y la pulpa de café. Del total de cuestionarios aplicados, el 37.3\% de los productores despulpa el café en su casa; el $34.7 \%$ en la finca y únicamente el $27.2 \%$ lo lleva a una cooperativa para beneficiarlo. El $31.5 \%$ dijo que las aguas mieles se depositan en una laguna de oxidación, el $23.5 \%$ manifestó que se tiran en el terreno. $10.1 \%$ de los consultados no tiene ningún método de tratamiento.

El $64.3 \%$ de los consultados manifestó que su finca no está certificada; esto representa un desafío para las organizaciones y para la institucionalidad cafetalera, puesto que existe una tendencia en el mercado internacional de 
comprar cafés orgánicos y cada vez con criterios de sostenibilidad. Los productores están conscientes que esto representa oportunidades al mejorar la calidad del café. A pesar de ello, existen prácticas que deberán analizarse si se desea aprovechar el potencial que existe en los cafés diferenciados.

Por ejemplo, el $54.2 \%$ de los productores de la región tienen diferentes tipos de cafés en su finca, solo el $34.9 \%$ de los consultados dijo tener una sola variedad. 58.2\% manifestó nunca haber realizado estudios de suelo.

\section{Gráfico 4: Tipos de café y estudios de suelo}
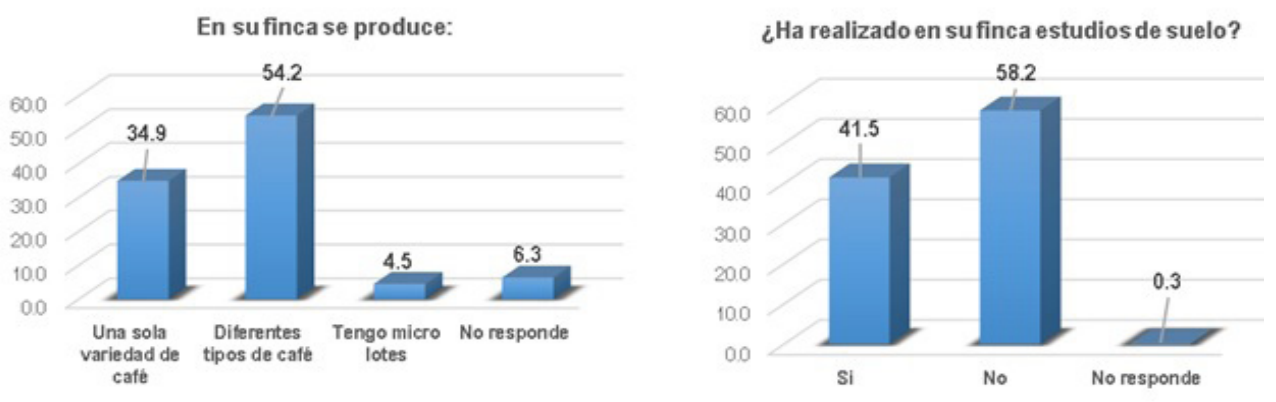

Fuente: Propia con datos de cuestionario UNAH - 2017/2018

Estos desafíos pueden encontrar solución en la medida que existan verdaderos procesos de coordinación institucional. En las fincas, todavía no se aprovecha el potencial que existe en la venta de servicios ecosistémicos; el 57.4\% de las familias productoras nunca han escuchado acerca de este tema. Las oportunidades dentro de la finca del productor son diversas; la venta de oxígeno, el cuidado de las fuentes de agua, la protección del bosque, la flora y la fauna, la belleza escénica y otros servicios ambientales, son parte de los ambientes prometedores en los cuales están inmersas las familias productoras de café en el occidente de Honduras.

\section{DISCUSIÓN}

La caficultura en Honduras está diseñada bajo una visión agroexportadora la cual corresponde a un modelo de desarrollo que ha puesto como prioridad el crecimiento económico de los distintos factores de producción. El crecimiento económico hondureño no ha podido resolver las desigualdades sociales. No se produce un efecto derrame de forma automática, por lo cual, se vuelve imprescindible plantearse nuevas formas de intervención; modelos alternativos que contemplen cambios y giros paradigmáticos que coloquen a la persona como el centro de toda intervención. Para 


\section{HACIA OTRO PARADIGMA DE ECONOMÍA POLÍTICA DEL CAFÉ Y DESARROLLO HUMANO \\ EN EL OCCIDENTE DE HONDURAS.}

construir un nuevo paradigma o modelo de la economía política del café y desarrollo humano, necesita partir desde la misma comunidad, con sus propias visiones hacia el futuro. Un modelo alternativo de intervención comunitario debe contemplar procesos arduos de formación y capacitación, para desnudar y desmantelar las premisas que han condicionado el pensamiento de las personas, puesto que "la miseria humana no es la falta de dinero, sino la falta de conocimiento de quienes somos" (Falck, 2000, p.2).

Un nuevo paradigma debe volver la mirada hacia lo local, con participación efectiva de amplios sectores. La familia productora debe representar la caficultura como propia para poder transfórmala. Deben reconocer el poder que en ellos radica. Deben fortalecer la institucionalidad por medio de su legitimización, debe cambiarse a las personas antes de cambiar las cosas (De Souza, et. al., 2006). Un nuevo paradigma de economía política de café y desarrollo humano, debe salirse de las premisas clásicas del desarrollo y debe volver la mirada hacia alternativas al desarrollo que incluyan una escuela de pensamiento alternativo, un observatorio de la caficultura regional, un proceso transparente de fortalecimiento organizativo, una mesa sectorial de actores alrededor de la caficultura y una obligada revisión de la funcionalidad institucionalidad.

La escuela de pensamiento busca conocimientos profundos en la región. No se trata de buscar alternativas porque hay muchas; se trata de encontrar pensamientos alternativos a esas alternativas (Santos, 2003). Seguir teniendo visiones lineales de la realidad nos conducirán a cometer los mismos errores, puesto que, no se pueden ignorar las lecciones del pasado (Stiglitz, 2012,). Se trata de buscar la construcción de caminos propios, que solo es posible al integrar una escuela de pensamiento que pueda hacer posibles los esfuerzos de deconstrucción cultural y descolonización epistemológica. Esta escuela deberá estar integrada por todos los actores que intervienen en la cadena de valor del café y los gestores del desarrollo. Deberá reconocerse que existen conocimientos científicos y saberes locales, esto hará posible el encuentro de la experiencia con la técnica, la tecnología y todos los avances de la ciencia.

Un observatorio de la caficultura en la región occidental, puede coordinarse con otros observatorios existentes. En este podrán estar incluidas las familias productoras, las universidades y los procesos de organización. El observatorio deberá crear una plataforma virtual para visibilizar el aporte de las familias productoras a la economía nacional. Esta plataforma puede crear las condiciones para aprovechar las oportunidades de mercado, para exponer las marcas y los cafés especiales de la región, para contactar compradores directos, con ello se acortarán los eslabones de la cadena lo cual se traducirá en mayores beneficios para las familias productoras. De 
la misma forma, esta plataforma podrá hacer visibles los cuidados al ambiente que el productor realice dentro de las fincas de café.

Un nuevo paradigma de economía política del café y desarrollo humano debe buscar fortalecer los procesos organizativos iniciados. De manera conjunta, se pueden mitigar los daños a los ecosistemas, se pueden buscar oportunidades de comercialización directa y se pueden aprovechar todos los subproductos de la producción del café. Para ello, es necesario fortalecer los procesos de cooperativismo regional y todos los actores relevantes que tienen incidencia directa e indirecta con la economía del café y el desarrollo humano en la región.

La creación de una mesa sectorial podrá utilizarse como brazo técnico de la caficultura regional, por medio de la mesa sectorial se pueden emprender reformas o creación de nuevas políticas cafetaleras. Podrá gestionar fondos para hacer realidad la instalación de la escuela de pensamiento y un observatorio de la caficultura. Esta mesa sectorial deberá estar integrada por todos los actores que intervienen en la región occidental de Honduras. De la misma forma, este estudio propone el fortalecimiento institucional. Debe revisarse el accionar de las instituciones que están alrededor de la caficultura; debe crearse una cultura cafetalera que al estar institucionalizada puedan integrarse otros actores relevantes para el bienestar de la población. La legitimización se ganará en la medida de que las familias productoras sientan que ellos son la prioridad en los procesos de cambio, que son tomados en cuenta en la toma de decisiones, que sientan inclusión y participación real en las estructuras de poder.

Por medio de una institucionalidad fortalecida, la caficultura puede crear las condiciones para avanzar hacia una cultura de consumo de buen café, hacia una mayor identidad con la región, hacia la creación de una industria que no solo contemple la exportación del grano, sino, aprovechar todas las potencialidades que están alrededor del café hondureño. El sistema educativo, las instituciones encargadas del bosque y agua, las organizaciones no gubernamentales de desarrollo, las fundaciones y empresas asociativas, las instituciones y cooperativas cafetaleras, los gobiernos locales; todos pueden integrarse de manera institucional para crear mejores condiciones alrededor de la caficultura. Se debe institucionalizar ferias, festivales y concursos del café en cada uno de los departamentos, esto significaría conectar la actividad cafetalera con otras industrias y actividades productivas del país. Por lo cual, todos podemos sumar esfuerzos para el engrandecimiento de Honduras.

Este estudio ha ido más allá de las estadísticas. Los informes de las instituciones cafetaleras y del mismo Gobierno, están llenos de cifras que corresponden a una realidad macroeconómica, sin embargo, dónde están los aspectos propios del bienestar de las familias, dónde se reflejan sus preocupaciones, dónde se encuentran 


\section{HACIA OTRO PARADIGMA DE ECONOMÍA POLÍTICA DEL CAFÉ Y DESARROLLO HUMANO \\ EN EL OCCIDENTE DE HONDURAS.}

sus sueños y aspiraciones por una mejor caficultura. Este estudio puede ser el inicio para posteriores investigaciones bajo una realidad dialógica con actores relevantes.

Las "estadísticas cuentan historias. Son tecno-representaciones dotadas de complejas historias culturales y políticas" (Escobar, 2007, p. 357). Las cifras y las estadísticas pueden denotar logros y beneficios para una economía, pero no necesariamente para el bienestar humano. por tal razón, este estudio puede servir de base para comprender mejor la realidad de las familias productoras, porque al final de todo, se trata de buscar pensamientos alternativos que nos invite a ir más allá, con visiones incluyentes, biocéntricas, espirituales y, especialmente, con un irrestricto respeto por la sostenibilidad de todas las formas de vida.

\section{CONCLUSIONES}

La comprensión de la economía política del café y desarrollo humano en la región occidental de Honduras, ha evidenciado por medio de este estudio, que necesita otra forma de intervenir; un nuevo paradigma que contemple obligadamente procesos de deconstrucción cultural, que desmantele un discurso desarrollista que ha penetrado con la implementación de dicotomías que condicionan la forma de pensar y actuar. Las concepciones tradicionales hacen ver la realidad como inalterable; modelos, recetas, estrategias que pareciera no se pueden cambiar.

La deconstrucción puede hacer posible otras miradas, otras visiones de la realidad; es debatir y cuestionar una forma de intervención que no ha brindado los impactos concebidos para el bienestar de la población. La descolonización epistemológica es desmantelar un discurso político, cultural e institucional. Es romper con dicotomías y diversas monoculturas que condicionan el pensamiento de la sociedad. La cadena productiva del café aporta considerables divisas al país, esto, en alguna medida, contribuye con el bienestar económico de las familias, puesto que la caficultura está repartida entre miles de familias.

Con los ingresos, las familias atienden el mejoramiento de sus viviendas, la salud, alimentación y educación de sus hijos. Sin embargo, es un proceso lento, de inversión y reinversión. La institucionalidad cafetalera está sustentada por el mismo productor. Las quejas son diversas: Poca asistencia técnica y difícil acceso a fuentes de financiamiento. Para la institucionalidad cafetalera los retos son considerables; mitigar los daños ambientales, avanzar en los procesos organizativos, acortar los eslabones de la cadena de valor, buscar iniciativas para dar valor agregado a la producción, son parte de los escenarios prospectivos. No se puede negar que la caficultura ha contribuido al bienestar humano, sin embargo, las estrategias de intervención deben 
revisarse para poder coordinar esfuerzos y encadenar otras actividades productivas de la región, con visiones más incluyentes, con justicia cognitiva y con irrestricto respeto hacia la madre Tierra.

\section{AGRADECIMIENTOS}

Este estudio agradece a la coordinación y a todo el equipo técnico del Doctorado en Ciencias del Desarrollo Humano. Ala Universidad Nacional Autónoma de Honduras por permitir fortalecer nuestras capacidades. A la Dirección de Investigación Científica y su oficina regional en el CUROC. A los colegas investigadores, a los estudiantes de la carrera de Comercio Internacional. A los técnicos y directivos regionales del Ihcafé y, especialmente, a las familias productoras de café del occidente de Honduras.

\section{BIBLIOGRAFÍA}

Bustelo, P. (1998). Teorías contemporáneas del desarrollo económico. Madrid, España: SINTESIS.

Bustelo, P. (1992). Economía del desarrollo. Un análisis histórico. Madrid, España: UCM.

Carranza, A. (2012). Historia y Cultura del Café en el Occidente de Honduras. Aromas, Montañas y Gente. Tegucigalpa, Honduras: PROMECAFE/IHCAFE/BID/ FOMIN. Impresiones Industriales.

De Souza Silva, J., Santamaría, J., Cheaz, J., Mato, M., Valle, S., Castro, A., Maestrey, A. Álvarez González, F., Ordoñez, J., Rodríguez, N., Chiliquinga, M., y Dolberg, N. (2006). ¿Quo Vadis, Transformación Institucional? La innovación de la innovación, del cambio de las cosas al cambio de las personas que cambian las cosas. San José, Costa Rica: Red Nuevo Paradigma.

Escobar, A. (2007). La Invención del Tercer Mundo: Construcción y reconstrucción del desarrollo. Caracas, Venezuela: Fundación Editorial el perro y la rana.

Escobar, A. (2002). Planeación, participación y desarrollo. Medellín, Colombia: Corporación Región.

Falck, M. (2000). La finca humana. Homenaje a don Elías Sánchez, un forjador de la esperanza rural. Tegucigalpa, Honduras: RDS - HN. CIDICCO, Cosecha, Zamorano, 


\section{HACIA OTRO PARADIGMA DE ECONOMÍA POLÍTICA DEL CAFÉ Y DESARROLLO HUMANO \\ EN EL OCCIDENTE DE HONDURAS.}

Vecinos Mundiales, MOPAWl, PASOLAC: IC. Proyecto Lempira Sur, CARITAS, EPIC, EARTH, Paul Mckay.

Hidalgo, Luis A. (1998). El pensamiento económico sobre desarrollo. De los mercantilistas al PNUD. España: Universidad de Huelva.

Hettne, B. (1990). Development Theory and the Three Worlds. London: Logman.

Hunt, D. (1989). Economic theories of development, an analysis of competing. London: Harvester Wheatsheaf.

Ihcafé (2019). Memoria cosecha (2018 - 2019. Tegucigalpa, Honduras: IHCAFÉ

Ihcafé (2017). Memoria cosecha 2016 - 2017. Tegucigalpa, Honduras: IHCAFÉ

Ihcafé (2016). Informe estadístico cosecha 2015 - 2016. Tegucigalpa, Honduras: Café de Honduras.

Jansen, K. (1993). Caféy Formas de Producción en Honduras. Revista Centroamericana de Economía, 14 (41), pp. 58 - 96.

Mckay, J. (1992). El modelo de desarrollo. Documentación social. Dialnet, (89), pp. 19-32.

Orellana, J. y Carranza, A. (2013). La Investigación Científica en la Historia y Cultura del Café en el Occidente de Honduras. La pequeña propiedad familiar. Paradigma, 20(32), pp. $135-152$.

O'neill, S. (2009). Percepciones de la pobreza y el bienestar subjetivo en el sur de Honduras: Aportes desde abajo para una sociedad más justa. (Tesis de doctorado). UNAH, Tegucigalpa, Honduras.

PLATS-UNAH (2005). El Occidente de Honduras, tierra de carencias y esperanzas: tendencias de desarrollo e impactos de los procesos de intervención pública en los últimos 50 años. Tegucigalpa, Honduras: Alin Editora.

Rahnema, M. (1996). Pobreza, en W. SACHS (editor), Diccionario del desarrollo. Una guía del conocimiento como poder. Perú: PRATEC.

Stiglitz, J. (2012). El Precio de la Desigualdad. El 1\% de la población tiene lo que el 99\% necesita. USA: Editorial TAURUS. 
Santos, B. (2012). De las dualidades a las ecologías. La Paz, Bolivia: Red Boliviana de Mujeres Transformando la Economía REMTE.

Santos, B. (2010). Descolonizar el Saber, Reinventar el Poder. Montevideo, Uruguay: Ediciones Trilce.

Sampieri, R., Fernández, C. y Baptista, P. (2006). Metodología de la Investigación. (4ta Ed.). México: McGraw-Hill.

Shiva, V. (2006). Como poner fin a la pobreza. REVISTA PASOS, (124), 7-9.

Santos, B. (2003). Critica de la Razón Indolente. Contra el Desperdicio de la Experiencia. Bilbao, España: Editorial Desclée de Brouwer, S.A. 